\title{
Stability of rectangular concrete-filled steel tubes
}

\author{
Ruslan Kanishchev ${ }^{1, *}$ \\ ${ }^{1}$ Technical University of Kosice, Faculty of Civil Engieering, Vysokoskolska 4, Kosice 042 00, \\ Slovakia
}

\begin{abstract}
The paper deals with the theoretical analysis of the influence of imperfections on the stability and carrying capacity of axially compressed cold-formed rectangular steel tubes filled with concrete, which use as bearing structures in the structural engineering, bridges, underground subway systems and tunnels. The behavior of the mentioned above composite structures under load were presented by numerical modelling in software ABAQUS. The support conditions of loaded edges of the steel section were considered as clamped in the models. The results of the analysis were shown the influence of imperfections on the stability and carrying capacity of the composite columns.
\end{abstract}

\section{Introduction}

Composite columns are a very important part of the composite structures, and, nowadays, are widely used in the erection of high-rise buildings, bridge constructions and in the underground subway systems and tunnels, in places with high compressive loads and relatively small bending moments. One type of composite columns are rectangular concrete-filled steel tubes (CFSTs). These elements have distinct advantages over hollow steel tubes as described in [1-4], but one of the main structural advantages is its significant resistance to loss of local and global stability, which allows designers to reduce the crosssection of the element.

Many researches and studies have been devoted to the field of CFSTs: Lee [5], Yang and Han [6], Uy [7] Krishan and Melnichuk [8]. Sakino et al. [9] tested specimens of centrally loaded concrete-filled steel tube short columns. Storozhenko et al. [10] conducted experimental tests on high-strength concrete-infilled steel tube columns subjected to eccentric loads. Liu et al. [11] performed experimental investigation on high strength concrete-filled steel square and rectangular hollow sections stub columns. Patel et al. [12] proposed a multiscale numerical model for simulating the interaction of local and global buckling behaviour of eccentrically loaded high strength rectangular CFSTs with large depth-to-thickness ratios. Ellobody \& Young [13] in their study presented an accurate nonlinear finite element model for the behaviour and design of axially loaded concretefilled square hollow section and rectangular hollow section steel tube columns.

*Corresponding author: ruslan.kanishchev@gmail.com 
Authors Kanishchev and Kvočák [14], Kang et al. [15] in their scientific work showed, that currently, standards already exist for the design of the rectangular concrete-filled steel tubes. The European Union uses Eurocode 4 [16], but the basic disadvantage of this standard is its limitations regarding the slenderness of the wall of the rectangular crosssection. The direction of research on the development of standards for the design of composite columns with concrete-filled class 4 hollow steel cross-sections, according to EN 1993-1-1 [17], which already lie beyond the validity of Eurocode 4, is an actual topic.

\section{Modeling of composite members in ABAQUS}

\subsection{General}

The theoretical analysis included the simulation of 2 samples of the hollow tubes and 4 samples of the concrete-filled rectangular steel tubes, which was generated in ABAQUS 6.13-4 (Fig.1) to determine the influence of standard imperfections on the stability and carrying capacity of axially compressed composite columns with and without welded end plates. An analysis was carried out on the rectangular cross section of tubes RHS 200x100x3 [18,19] (Class 4 according to [17]) with imperfections according to EN 10219 [19] (see Fig. 2) and without imperfections, the length of the column is $2900 \mathrm{~mm}$.

There are three main parameters that need to be considered to simulate the actual behavior of concrete-filled rectangular hollow steel tube columns. These parameters are the confined concrete, the steel tube and the interface between the concrete and the steel tube. In addition to these parameters, the choice of the element type and mesh size that provide accurate results with reasonable computational time is also important in simulating the composite columns.
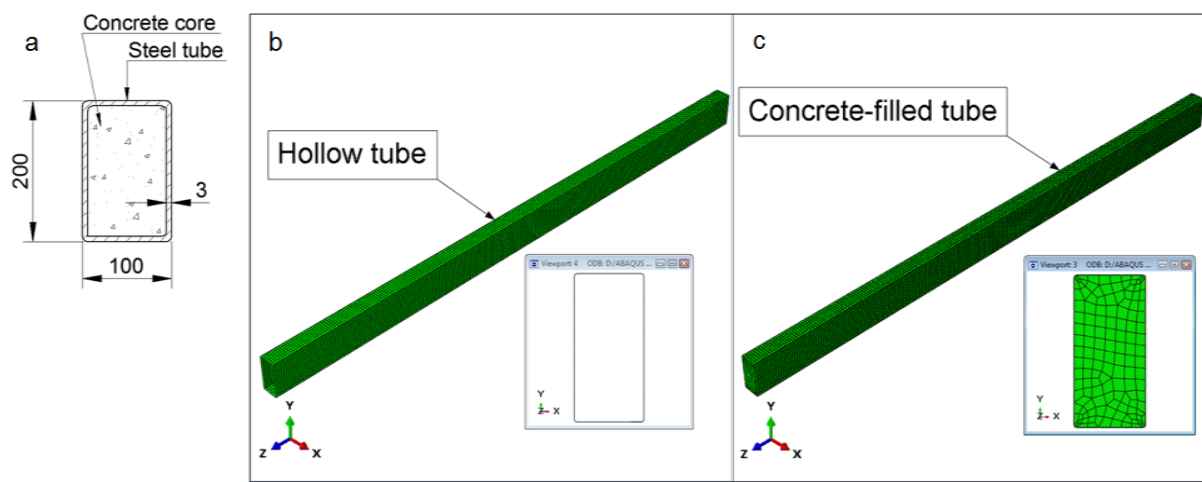

Fig. 1. (a) researched concrete-filled hollow cross-section; (b) 3D model of hollow tube; (c) 3D model of concrete-filled tube.

a

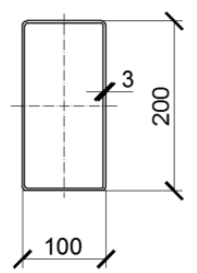

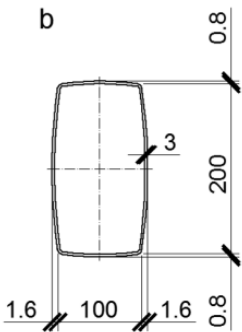

Fig. 2. Cross-section RHS 200x100x3: (a) without imperfection; (b) with imperfection. 


\subsection{Finite element type and mesh}

A library of ABAQUS [20] elements was used in modelling. The 4-noded doubly curved shell elements with reduced integration S4R is used to model the buckling behavior of the steel tube. The S4R element has six degrees of freedom per node and provides accurate solution to most applications. The element allows for transverse shear deformation, which is important in simulating thick shell elements. The element also account for finite strain and suitable for large strain analysis. Fine mesh of three-dimensional 8-Node solid elements (C3D8) is used to model the concrete infilled. Different mesh sizes have been tried to choose the reasonable mesh that provides both accurate results and less computational time. It is found that a maximum mesh size of $15 \mathrm{~mm}$ (length): $15 \mathrm{~mm}$ (width): $15 \mathrm{~mm}$ (depth), for most of the elements, can achieve accurate results.

\subsection{Boundary conditions and load applications}

The steel tube and the concrete core are left completely unrestrained in all directions to allow any possible form of deformation in the column. A rigid "fictive" plate is modelled at both the top and bottom of the specimens to simulate the platens in an actual testing machine. The top and bottom "fictive" plates have hinge boundary condition applied at its reference node. The load was applied on the top "fictive" plate through her reference node in the direction of " $z$ " axis (see Figs 4-9). The loading of columns was modelled as shortterm, rising steadily at a constant rate, introduced through the plate of a hydraulic press. The simulation of boundary conditions of the walls of the hollow and concrete-filled crosssection has been created by using the fictive weld of the end (support) plates on both ends of the tube, which means that it was prevented from rotation of this edges (Figs 3a-3c).

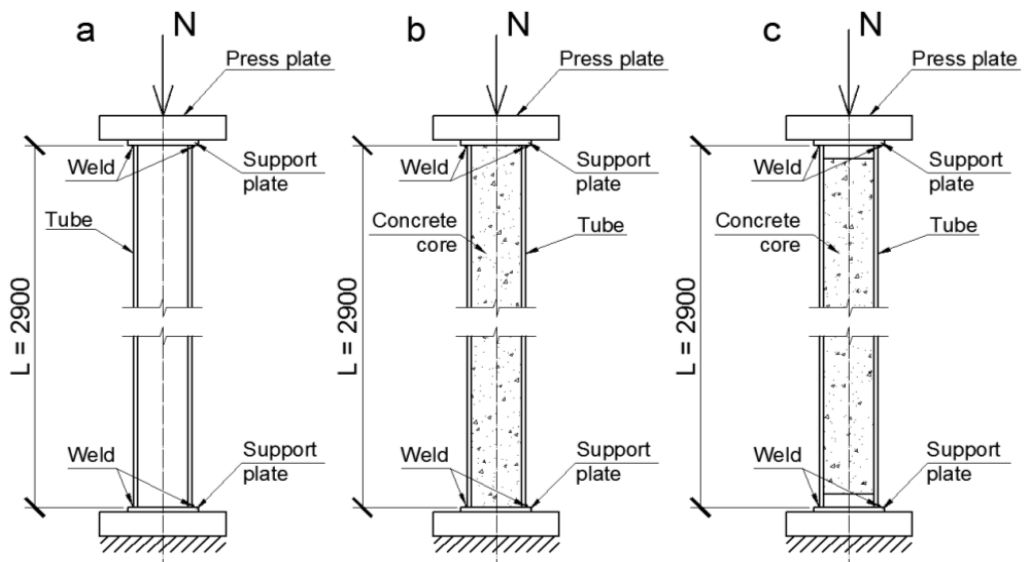

Fig. 3. Scheme of loading composite columns: (a) on the hollow steel tube through the welded support plate; (b) on the steel tube and concrete core through the welded support plate; (c) on the steel tube through the welded support plate

\subsection{Material modeling of steel tube and concrete core}

The material characteristics of the research members were defined by material tests. When modelling the steel cross-sections, were used the material characteristics: yield strength $\mathrm{f}_{\mathrm{y}}=374.7 \mathrm{MPa}$, elastic modulus $\mathrm{E}=205.9 \mathrm{GPa}$, Poisson's ratio in elastic state $v=0.3$ were used. Behaviour of material is modeled as elastoplastic with linear hardening according to EN 1993-1-5 [21]. The core of the hollow section was modelled from concrete C20/25 
according to EN 1992-1-1 [22]: compressive strength of concrete $f_{c m}=21.4 \mathrm{MPa}$, $\mathrm{f}_{\mathrm{cm}, \text { cube }}=27.94 \mathrm{MPa}$, elastic modulus $\mathrm{E}=26.47 \mathrm{GPa}$. The confined concrete model adopted by $\mathrm{Hu}$ et al [23] is used to define the stress-strain behaviour for concrete in the modeling procedure. The interaction of the steel and concrete elements was modelled by means of two components: the "normal" one as compression of concrete on the steel section and the "tangential" one as shear resistance at the steel-concrete interface. The coefficient of friction was regarded as 0.3 .

\section{Results and discussion}

The deformation and carrying capacity of investigated members are shown on Figs. 4-9 and Table 1. According to research targets, the following characteristic resistances are important: $N_{c r}$ - the measured numerical critical force of the first buckling form (ABAQUS); $N_{p l}$ - the measured numerical force, acted on tested member before the beginning of continuous strains $\varepsilon$ and deflections of the webs $w$ (ABAQUS).

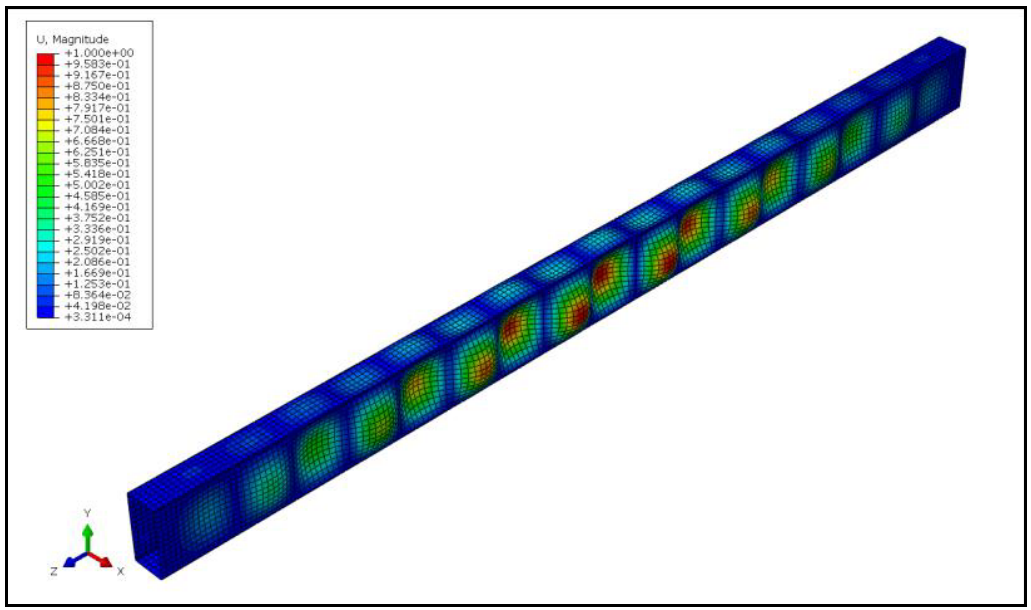

Fig. 4. First buckling form of the hollow steel tube without imperfections

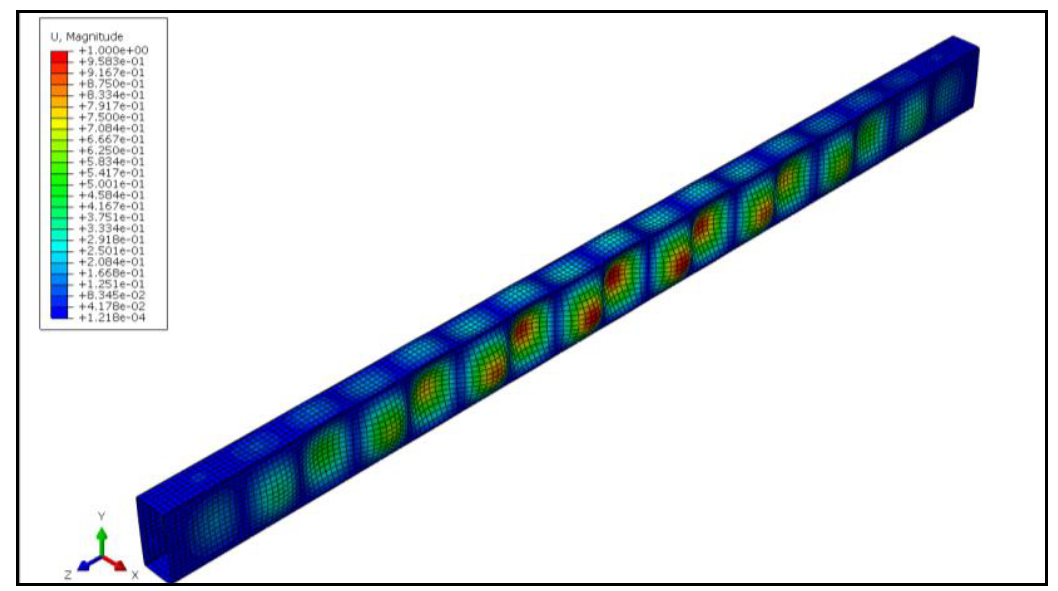

Fig. 5. First buckling form of the hollow steel tube with imperfections 


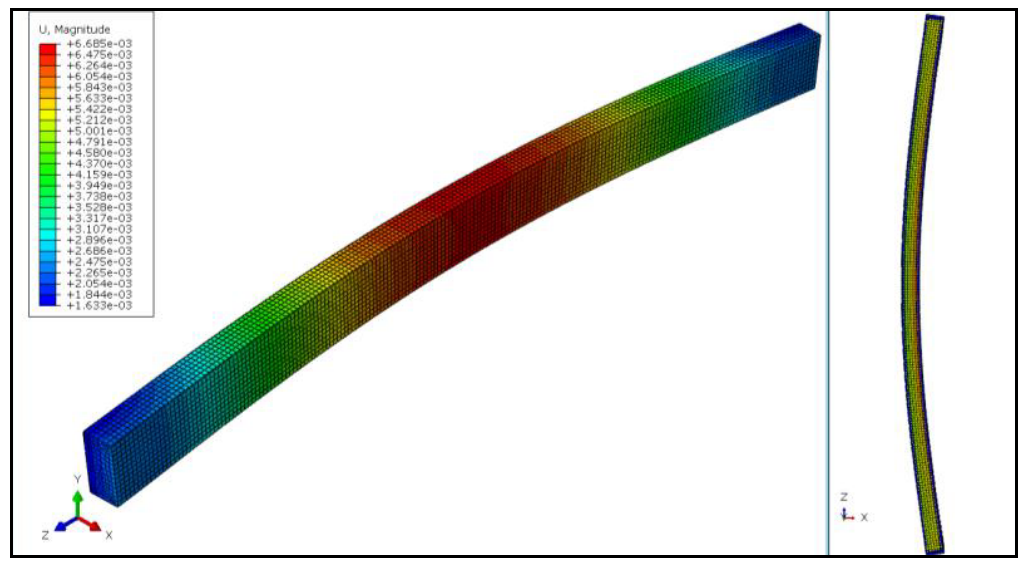

Fig. 6. 3D deformation of the CFST without imperfections

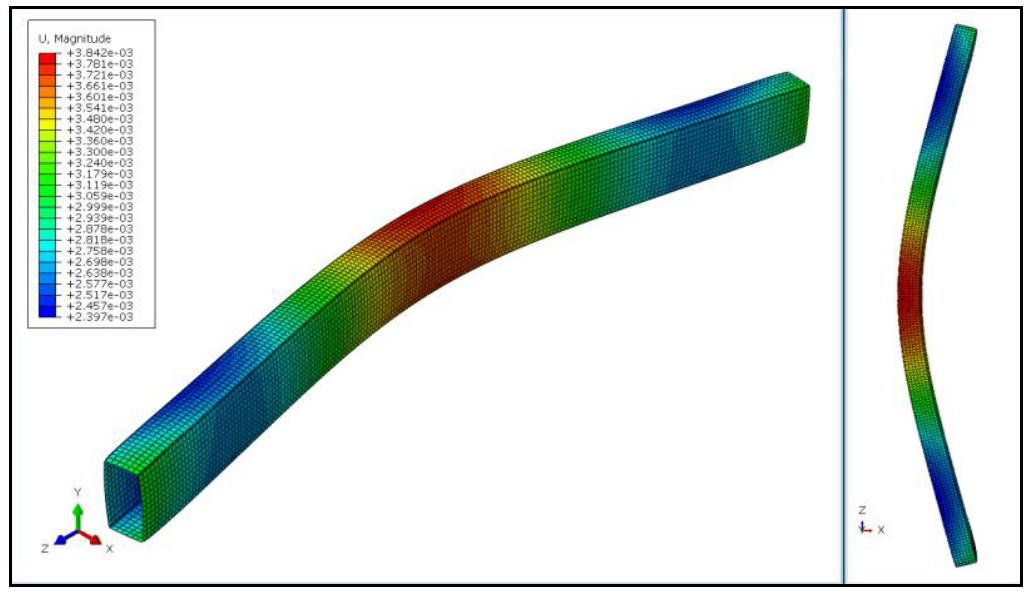

Fig. 7. 3D deformation of the CFST with imperfections

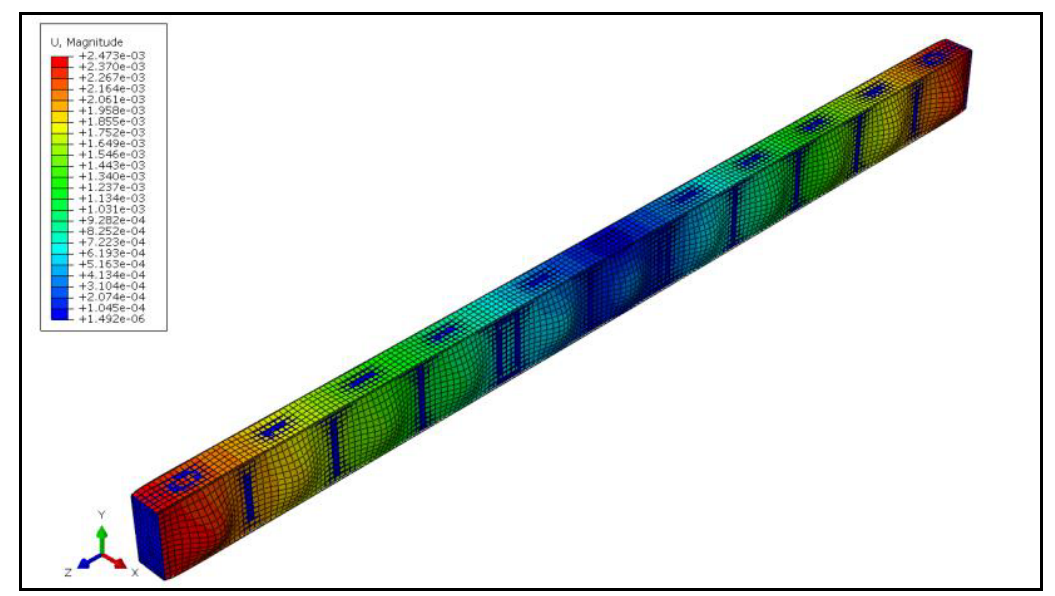

Fig. 8. 3D deformation of the CFST without imperfections, when loading the steel part of the composite cross-section 


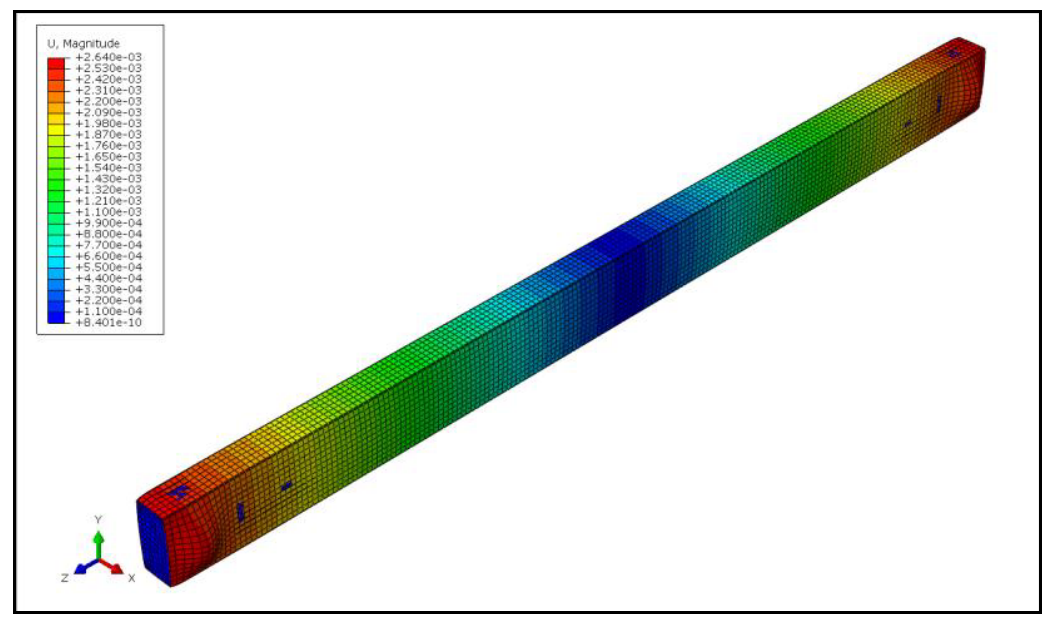

Fig. 9. 3D deformation of the CFST with imperfections, when loading the steel part of the composite cross-section

Table 1. Limit loads of tested members.

\begin{tabular}{|c|c|c|}
\hline Tested member & $\begin{array}{c}\boldsymbol{N}_{c r} \\
{[\mathbf{k N}]}\end{array}$ & $\begin{array}{c}\boldsymbol{N}_{p l} \\
{[\mathbf{k N}]}\end{array}$ \\
\hline Hollow steel tube without imperfections & 381.92 & - \\
\hline Hollow steel tube with imperfections & 422.91 & - \\
\hline CFST without imperfections & - & 933.95 \\
\hline CFST with imperfections & - & 995.68 \\
\hline $\begin{array}{c}\text { CFST without imperfections, when loading the steel part of the composite } \\
\text { cross-section }\end{array}$ & - & 566.10 \\
\hline $\begin{array}{c}\text { CFST with imperfections, when loading the steel part of the composite cross- } \\
\text { section }\end{array}$ & - & 601.65 \\
\hline
\end{tabular}

The numerical models of the researched members in software ABAQUS shown, that critical force of the steel tube with imperfection is higher by $10 \%$ than in the case without imperfection (see Table 1). The first buckling form in these cases remains unchanged (see Fig. 4-5).

In the case with CFSTs, the critical elastic stresses not found, because the behavior of the steel material lies in plastic field. When loading the CFST with and without imperfections, the local buckling of the steel part of the cross-section hasn't appeared and the columns has lost the global stability (see Fig. 6-7). The numerical resistance force of the CFST with imperfection is higher by $6.2 \%$ than in the case without imperfection.

The concrete core of the composite columns, when loading the steel part of the crosssection, increases the local stability of the steel part of composite cross-section (Tab.1) to extent that, the local buckling phenomenon occurs in the field of plastic material behavior. The numerical resistance force of the researched member with imperfection is higher by $6 \%$ than in the case without imperfection. The deformations of local buckling in the case with member with imperfection have appeared closer to the ends of this member (see Fig. 8-9). 


\section{Conclusions}

Based on the results of this theoretical analysis as general conclusions of the research are the following:

1. One of the basic types of composite sections in the form of a rectangular steel tube with a profile of RHS 200x100x3 (EN 10219), filled with concrete, which lie beyond the validity of Eurocode 4, was investigated.

2. The geometrical imperfections of the cross-section, according to standard EN 10219, has the influence on the stability and carrying capacity of the axially compressed composite columns with cross-section in the form of cold-formed rectangular steel tubes RHS 200x100x3 filled with concrete.

3. The above mentioned theoretical analysis is one part of the research oriented to determine the impact of loss the stability of rectangular concrete-filled steel tubes in terms of their resistance. This direction of research is an actual topic, because the concrete core in thin walled cold-formed rectangular steel tubes significantly increases the resistance from the loss of local and global stability.

\section{Acknowledgements}

The paper presented was supported by the projects: VEGA 1/0188/16 "Static and Fatigue Resistance of Joints and Members of Steel and Composite Structures" of the Scientific Grant Agency of the Ministry of Education, science, research and sport of the Slovak Republic and the Slovak Academy of Sciences.

\section{References}

1. R. Kanishchev, V. Kvočák, Vedecko-výskumná činnost' UIS 2013, 107-116, (2014)

2. V. Kvočák, G. Varga, R. Vargova, Proc. Eng. 40, 469-474 (2012)

3. I. Garanzha, N. Vatin, J. Appl. Mech. and Mat. 633-634, 965-971 (2014)

4. I.A. Duvanova, I.D. Salmanov, Constr. of U. Build. and Struct. 6(21), 89-103 (2014)

5. S. Lee, J. Steel and Comp. Str. 7 (2), 135-160 (2007)

6. Y.Yang, L. Han, J. of Constr.Steel Res. 65, 1617-1630 (2009)

7. B. Uy, J. of Constr. Steel res. 64, 748-754 (2008)

8. A.N. Krishan, A.S. Melnichuk, Bulletin of the Nosov MSTU 3, 51-54 (2012)

9. K. Sakino, H Nakahara, S. Morino, I. Nishiyama, J. Str. Eng. 130(2), 180-188 (2004)

10. L.I. Storozhenko, D.A., Ermolenko, O.V. Demchenko, Efficiency of resource energy of technology in the construction industry of region 4, 288-292 (2014)

11. D. Liu, W.M. Gho, J. Yuan, Constr. S. Res. 59(12), 1499-1515 (2003)

12. V. I. Patel, Q. Q. Liang, M. Hadi, J. Inter. and M. M.. 5 (2), 91-104 (2012)

13. E. Ellobody, B. Young, T.-W. Str. 44, 919-930 (2006)

14. R. Kanishchev, V. Kvočák, IABSE El. in Str. Nara, 1-8 (2015)

15. W.-H. Kang, B. Uy, Z. Tao, S. Hicks, J. Adv. Steel Constr. 11 (2), 165-184 (2015)

16. EN 1994-1-1, Eurocode 4: Design of composite steel and concrete structures. Part 1-1: General rules and rules for buildings (CEN, Brussels, 2004)

17. EN 1993-1-1, Eurocode 3: Design of steel structures. Part 1-1: General rules and rules for buildings (CEN, Brussels, 2005) 
18. EN 10219-1: Cold formed welded structural hollow sections of non-alloy and fine grain steels. Part 1: Technical delivery conditions (CEN, Brussels, 2006)

19. EN 10219-2: Cold formed welded structural hollow sections of non-alloy and fine grain steels. Part 2: Technical delivery conditions (CEN, Brussels, 2006)

20. Simulia, Abaqus 6.13: Analysis Users Guide. Volume I (Dassault Systems, 2013)

21. EN 1993-1-5, Eurocode 3: Design of steel structures. Part 1-5: Plated structural elements (CEN, Brussels, 2008)

22. 1992-1-1, Eurocode 2: Design of concrete structures. Part 1-1: General rules and rules for buildings (CEN, Brussels, 2005)

23. H-T. Hu, et al., J. Str. Eng. 129 (10), 1322-1329 (2003) 